Article

\title{
Self-Organizing Map Network-Based Soil and Water Conservation Partitioning for Small Watersheds: Case Study Conducted in Xiaoyang Watershed, China
}

\author{
Lingxia Wang ${ }^{1}$, Zhongwu Li ${ }^{1,2, *}$, Danyang Wang ${ }^{1}$, Xiaoqian $\mathrm{Hu}^{1}$ and Ke Ning ${ }^{1}$ \\ 1 College of Environmental Science and Engineering, Hunan University, Changsha 410082, China; \\ wanglingxia@hnu.edu.cn (L.W.); sapphire@hnu.edu.cn (D.W.); huxiaoqian@hnu.edu.cn (X.H.); \\ kening@hnu.edu.cn (K.N.) \\ 2 College of Resources and Environmental Sciences, Hunan Normal University, Changsha 410081, China \\ * Correspondence: lizw@hnu.edu.cn; Tel.: +86-0731-8864-0078
}

Received: 16 February 2020; Accepted: 6 March 2020; Published: 9 March 2020

\begin{abstract}
Soil and water conservation partitioning (SWCP) considers complex environmental statutes and development demands and serves as a scientific basis for conducting soil erosion management and practice. However, few studies have researched partitioning in small watersheds $\left(<50 \mathrm{~km}^{2}\right)$, and guidelines for enabling region-specific measures are lacking. In this study, the Xiaoyang watershed located in the red soil region of southern China was selected as a representative small watershed in which to conduct partitioning. The pressure-state-response (PSR) model was used as a framework for establishing an indicator system that included soil erosion sensitivity, the soil erosion condition, and ecosystem services. With three soil and water conservation variables as the input layer, a one-dimensional self-organizing map was applied to identify clusters in the small watershed. The silhouette width was evaluated to determine the optimal number of regions. Based on the associated results, the Xiaoyang watershed was divided into five regions accounting for $82 \%$, $9 \%, 8 \%, 2 \%$, and $1 \%$ of the total area, respectively. This study provides a framework on which region-specific soil erosion measures can be planned, and it also provides a partitioning method that can be employed in other areas.
\end{abstract}

Keywords: Land management; Soil erosion; Ecosystem services

\section{Introduction}

Human influences and natural factors (such as topography, climate, soil properties, and land cover) induce various types of soil erosion, and each type requires different management [1-3]. As the red soil region of southern China suffers from water erosion induced by heavy rainfall, adopting a no-tillage practice with mulching on farmland and increasing the vegetation coverage on forestland would assist considerably in controlling water erosion [4,5]. However, socio-economic factors restrict measures that can be employed to implement soil and water conservation management practices, and the economic statuses of farmers and the region determine any investments made to conserve soil and water [6]. Therefore, to prevent and control soil erosion, soil and water conservation measures need to be designed in accordance with the needs of both the local environment and the local inhabitants, and doing so is complex [7].

Partitioning is an important focus of geographical studies and is used as a guide during regional construction and development. Partitioning for soil and water conservation specifically links comprehensive controls on soil and water loss to socio-economic strategies based on a spatial understanding of the cause and intensity of soil erosion and the extent to which the soil is damaged [8]. Since the 1950s, soil and water conservation partitioning (SWCP) has been used as an effective tool to 
implement region-specific measures in China [9]. SWCP involves a comprehensive understanding of socio-economic development and the quality of the eco-environment. It is employed to divide a certain area into distinct regions, mainly with respect to the causes, driving forces, and characteristics of soil erosion in the various areas, with the aim of tailoring targeted monitoring and management and preparing scientific planning for regional sustainable development within the different partitions $[10,11]$. SWCP is uniquely applicable to China to a certain extent because China has a vast territory with significant regional differentiation (with respect to the natural environment and socio-economics), and has a system that eliminates the private ownership of land; therefore, the Chinese government can enact land policies and decide the direction of development based on SWCP results.

To date, most SWCP schemes have considered the natural environment, socio-economic situation, soil erosion types, and other elements in the region, and have provided an effective tool for strategic planning. Partitioning uses an evaluative and cluster-based approach to organize spatial units according to their similarity from a technical perspective [12]. In previous studies, administration cells, such as towns and counties, have usually been considered as spatial units. However, because of large administrative unit sizes, there are obvious differences between the natural factors, socio-economic conditions, and soil erosion features within one spatial unit, which makes it difficult to make plans within one region to prevent soil erosion. Although SWCP has been employed on from country up to province scales, the partitioning of small watersheds $\left(<50 \mathrm{~km}^{2}\right)$ remains uncommon. Nevertheless, conducting SWCP for small watersheds would avoid such a problem by determining pixels with a single attribute as a particular spatial unit. In the early 1980s, the Ministry of Water Resources of the People's Republic of China determined that small watersheds $<50 \mathrm{~km}^{2}$ in size were the most rational unit size for use in enabling the comprehensive control of soil and water loss [13]. Over the past 30 years, comprehensive management plans have been conducted in more than 10,000 small watersheds, covering a total area of $380,000 \mathrm{~km}^{2}$ [14]. However, local management agencies now require a more specific scheme to guide soil management practices, and SWCP for small watersheds is an effective method that can be used to comprehensively control soil erosion.

Soil erosion is a major threat to ecosystems and it impairs ecosystem services; however, current studies using SWCP have barely considered the ecosystem services within the targeted area. In some partition schemes, although values from different ecosystem service categories have been calculated and the dominant ecosystem services of each region have been identified, it was only used to name each region [11]. Therefore, ecosystem services do not have a main influence on partitioning results and have only been included as an accessory. Other studies have integrated several ecosystem services associated with soil and water conservation into the indicator system, such as soil formation and conservation $[15,16]$; however, as ecosystem tradeoffs exist, focusing on upgrading a certain ecosystem service could impair one or more other services, which could thus lead to a decline in unexpected ecosystem services [17-19]. For example, since 1999, the "Grain to Green" revegetation program has effectively increased soil formation and conservation on the semi-arid Loess Plateau in China, but it has also led to a decline in hydrological regulation and promoted water shortages for the population $[20,21]$. Therefore, to realize improvements in total ecosystem services when conducting soil and water conservation projects, all categories of ecosystem services should be evaluated in the practice of partitioning.

With the development of satellite imaging technology and statistical packages, traditional SWCP methods have gradually transformed from being qualitative to quantitative. In recent years, new methods, such as artificial neural management and fuzzy cluster analysis, have been widely used in pattern recognition and classification [22]. The self-organizing map (SOM) is an unsupervised neural network methodology that can project high-dimensional input data onto a low dimensional space. Due to the robust clustering function of the SOM, it has been successfully applied in the partitioning of precipitation, hydrology, and landscape $[8,23,24]$. However, although SOM is not a new method, it has barely been applied in SWCP. 
The Xiaoyang watershed is a typical small watershed in the hill red soil region of southern China that is experiencing severe soil erosion. Taking the Xiaoyang watershed as an example, the aims of this study were: (1) to propose a modified indicator system that integrates all categories of ecosystem services, (2) to quantitatively divide the SWCP using SOM, and (3) to obtain an SWCP scheme with a region-specific measures distribution. This study would be an example for other small watersheds with serious soil erosion in the hill red soil region of southern China to provide a scientific basis for the comprehensive control of soil erosion and water loss.

This paper is organized as follows: The study area, indicator system, and partitioning method are described in Section 2. The spatial pattern of three soil and water conservation variables calculated using the indicator system and the evaluation and analysis of the SWCP scheme are presented in Section 3. Section 4 discusses the selection of partitioning methods and mitigation measures based on SWCP. Section 5 provides conclusions.

\section{Methods}

\subsection{Study Area}

The Xiaoyang watershed $\left(26^{\circ} 15^{\prime}-26^{\circ} 20^{\prime} \mathrm{N}, 116^{\circ} 02^{\prime}-116^{\circ} 07^{\prime} \mathrm{E}\right)$ covers an area of $47.6 \mathrm{~km}^{2}$ and is located in Jiangxi province, southeastern China (Figure 1). It lies within the basin of the Meijiang River, which is a major tributary of the Yangtze River. The area experiences a subtropical humid monsoon climate with a mean annual temperature of $19^{\circ} \mathrm{C}$ and a mean annual precipitation of $1551 \mathrm{~mm}$ (mostly concentrated from April to June). In 2015, the Xiaoyang watershed was labeled a key small watershed area that is undergoing soil and water loss, and there is an aim toward mitigating the intense soil erosion and increasing rural incomes.

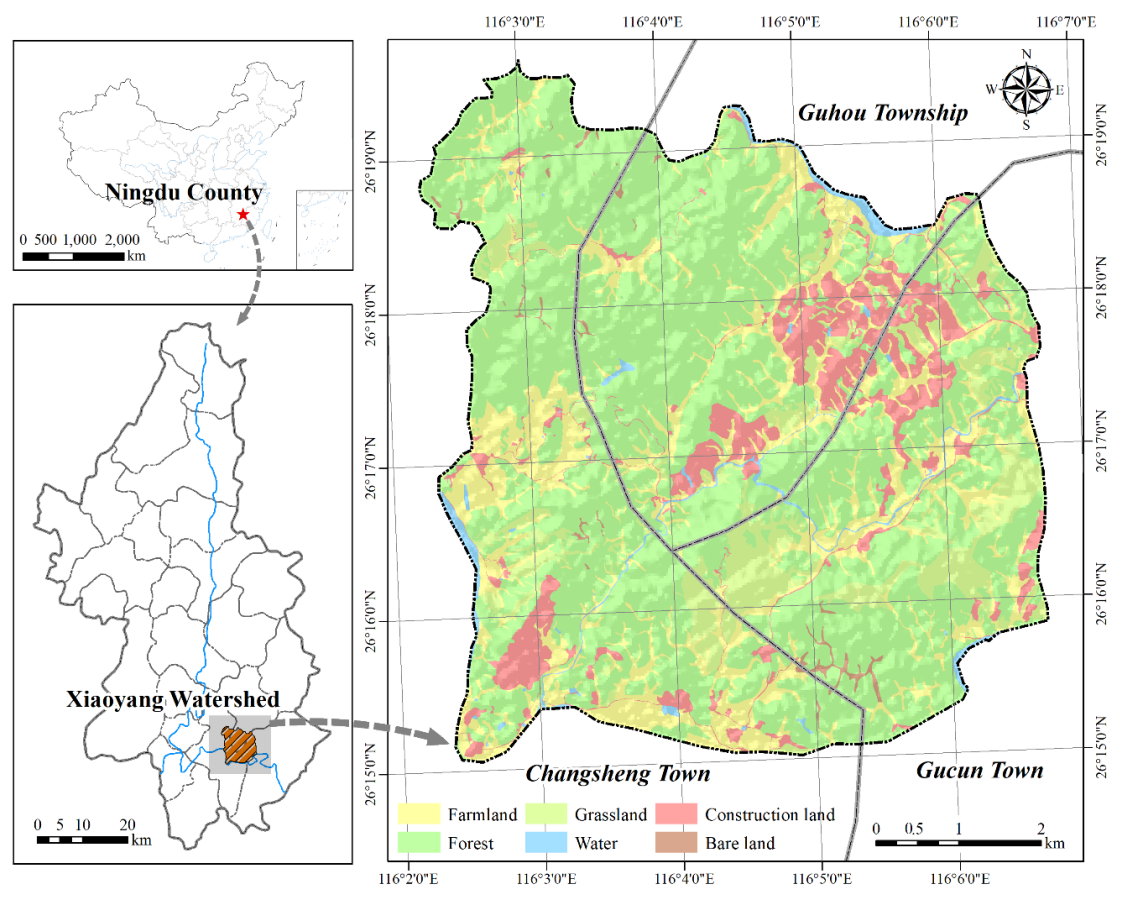

Figure 1. Location and land cover of Xiaoyang watershed.

The watershed mostly comprises hills and mountains with steep slopes, red soils, and paddy soils that have a hyper-sediment concentration and low natural fertility. Soil erosion occurring within the watershed is mostly dominated by hydraulic erosion that is mainly induced by intense rainfall and the steep slopes. By the end of 2015, the Xiaoyang watershed had a total population of 7680 at a density of 164 per $\mathrm{km}^{2}$. Human influences, such as population growth, infrastructure construction, and deforestation, have enabled secondary forest cover (represented by Pinus massoniana) to become the 
major vegetation type at a low coverage rate. The agricultural industry within the Xiaoyang watershed is very simple and is mainly dominated by crop farming; food crops provide a large proportion of farming incomes and the output value of the cash crops and forest fruits is low.

\subsection{Indicator System}

We based the indicator system on the pressure-state-response (PSR) concept model proposed by the Organization of Economic Cooperation and Development (OECD) and the United Nations Environment Program (UNEP). The PSR model is a causal framework involving causes and effects that influence a measurable state [25], and it has been widely used to evaluate land use and natural resources [26,27]. It has also been applied to construct an indicator system for partitioning; for example, Peng et al. [28] used the PSR framework to build an indicator system with a climatic background that included the vegetation condition to enable soil conservation service partitioning in the Inner Mongolia Autonomous Region.

We selected the PSR model to build the indicator system (Table 1) because the three dimensions of the model can completely reflect the needs, basis, and goals of SWCP. Specifically, the pressure dimension $(\mathrm{P})$ explains the appearance and different magnitudes of soil erosion within the watershed. Spatial heterogeneity results from human activities (such as land use) and natural factors (such as surface slope and vegetation coverage) on a site to the watershed scale, which expose soils to varying pressures and determine their sensitivity to erosion. This results in the distribution of the existing soil erosion condition within the watershed, which is represented by the state dimension (S), and the response dimension $(\mathrm{R})$, which represents the adjustment by human society to its ecosystem services and how the watershed ecosystem reacts to soil erosion, where restoration is the goal of soil and water conservation partitioning. In traditional PSR models, the response dimension shows the degree of the social response to environmental concerns and changes. However, the studied watershed lacks concentrated measures and management to mitigate soil erosion. Although residents have made certain associated efforts on a site scale, these have not influenced the entire watershed. Therefore, the response dimension in this study refers to the adaptation of ecosystems to change and not to the reaction of human society to the impaired environment.

Table 1. Indicator system used for partitioning.

\begin{tabular}{|c|c|c|}
\hline Dimension & Factor & Indicator \\
\hline Pressure & Soil erosion sensitivity & $\begin{array}{c}\text { Slope } \\
\text { Land use } \\
\text { Vegetation fractional coverage }\end{array}$ \\
\hline Status & Soil erosion condition & Soil erosion intensity \\
\hline Response & Ecosystem services & Value of ecosystem services \\
\hline
\end{tabular}

\subsubsection{Pressure Dimension}

The pressure dimension is represented by the soil erosion sensitivity and has three indicators. In the Revised Universal Soil Loss Equation (RULSE), five factors (including rainfall erosivity, soil erodibility, slope and slope length, vegetation coverage, and soil and water conservation measures) are considered in the calculation. As it is unlikely that the climatic regime varies considerably within the watershed, soil properties are mainly determined by land use, and few erosional control measures are currently in operation; therefore, we selected slope, land use, and the vegetation fractional coverage (VFC) to reflect the soil erosion sensitivity to be representative of the pressure dimension.

The slope determines the stability of the soil surface and is positively related to erosion sensitivity. We calculated the slope based on DEM data (30-m resolution, data source: www.gscloud.cn/sources/) and divided it into six grades according to the Chinese Soil Erosion Classification Standard (CSECS No. SL190-2007): $<5^{\circ}, 5^{\circ}-8^{\circ}, 8^{\circ}-15^{\circ}, 15^{\circ}-25^{\circ}, 25^{\circ}-35^{\circ},>35^{\circ}$. 
The vegetation canopy interception and soil-reinforcement via roots can effectively reduce the risk of soil erosion. As an indicator of the combination of natural factors and human activities, vegetation coverage can be used to assess the impact of vegetation on soil erosion sensitivity, and it is defined as:

$$
\mathrm{VFC}=\frac{\mathrm{NDVI}-\mathrm{NDVI}_{\min }}{\mathrm{NDVI}_{\max }-\mathrm{NDVI}_{\min }}
$$

where NDVI is the normalized differential vegetation index acquired from the Global Moderate Resolution Imaging Spectroradiometer (MODIS) vegetation index data set, and $\mathrm{NDVI}_{\max }$ and $\mathrm{NDVI}_{\min }$ are the maximum and minimum values of NDVI in the study area, respectively. Land use mainly reflects the disturbance of the surface cover due to human activities. In this paper, land use was visually interpreted from the satellite imagery data of Gaofen-2 according to the land resource classification system of the Chinese Academy of Sciences. Sun et al. [29] studied the soil erosion sensitivity in Leishan county, which shares a similar climate and soil erosion type with that of the Xiaoyang watershed. We, therefore, established a classification scale table of soil erosion sensitivity (Table 2) in the watershed based on their study.

Table 2. Soil erosion sensitivity classification where i (lowest)-vi (highest) indicate different levels of sensitivity.

\begin{tabular}{|c|c|c|c|c|c|c|c|}
\hline \multirow{2}{*}{\multicolumn{2}{|c|}{ Land Use }} & \multicolumn{6}{|c|}{ Slope $\left({ }^{\circ}\right)$} \\
\hline & & $0-5$ & $5-8$ & 8-15 & $15-25$ & $25-35$ & $>35$ \\
\hline \multirow{5}{*}{$\begin{array}{l}\text { Percentage of forestry and } \\
\text { grass coverage in } \\
\text { non-cultivated land }(\%)\end{array}$} & $75-100$ & $\mathrm{i}$ & i & i & i & i & $\mathrm{i}$ \\
\hline & $60-75$ & $\mathrm{i}$ & $\mathrm{i}$ & $\mathrm{i}$ & $\mathrm{i}$ & ii & ii \\
\hline & $45-60$ & $\mathrm{i}$ & $\mathrm{i}$ & $\mathrm{i}$ & ii & ii & iii \\
\hline & $30-45$ & i & $\mathrm{i}$ & ii & ii & iii & vi \\
\hline & $0-30$ & $\mathrm{i}$ & ii & ii & iii & vi & $\mathrm{v}$ \\
\hline \multirow{2}{*}{ Cultivated slope land } & Paddy field & $\mathrm{i}$ & $\mathrm{i}$ & i & $\mathrm{i}$ & i & $\mathrm{i}$ \\
\hline & Dry field & $\mathrm{i}$ & ii & iii & vi & $\mathrm{v}$ & vi \\
\hline \multirow{4}{*}{ Other types of land use } & Water area & $\mathrm{i}$ & $\mathrm{i}$ & i & $\mathrm{i}$ & i & $\mathrm{i}$ \\
\hline & Construction land & $\mathrm{i}$ & $\mathrm{i}$ & $\mathrm{i}$ & $\mathrm{i}$ & $\mathrm{i}$ & $\mathrm{i}$ \\
\hline & Mining land & $\mathrm{i}$ & ii & iii & vi & $\mathrm{v}$ & $\mathrm{vi}$ \\
\hline & Bare land & $\mathrm{i}$ & $\mathrm{i}$ & ii & iii & vi & $\mathrm{v}$ \\
\hline
\end{tabular}

\subsubsection{State Dimension}

The state dimension was measured using the current state and distribution of soil erosion. We used the soil erosion intensity to reflect the current soil erosion conditions, where the soil erosion intensity refers to the soil erosion grade divided by the amount of soil erosion per unit area per unit period. The intensity of soil erosion $\left(\mathrm{t} \mathrm{km}^{-2} \mathrm{a}^{-1}\right.$ ) was divided into six grades according to the CSECS: $<500$ (not apparently eroded), 500-2500 (slightly eroded), 2500-5000 (moderately eroded), 5000-8000 (severely eroded), 8000-15,000 (highly eroded), >15,000 (extremely eroded). The amount of soil erosion was calculated using the Chinese Soil Loss Equation (CSLE), which is a modified soil erosion prediction model for soil erosion based on RUSLE, which has been widely applied in China, and is given as:

$$
\mathrm{M}=\mathrm{R} \times \mathrm{K} \times \mathrm{LS} \times \mathrm{B} \times \mathrm{E} \times \mathrm{T},
$$

where $M$ is the annual average soil erosion amount $\left(t \mathrm{ha}^{-1} \mathrm{a}^{-1}\right.$, where $\left.1 \mathrm{t} \mathrm{ha}^{-1} \mathrm{a}^{-1}=100 \mathrm{t} \mathrm{km}^{-2} \mathrm{a}^{-1}\right), \mathrm{R}$ is the rainfall erosivity factor ( $\left.\mathrm{MJ} \mathrm{mm} \mathrm{ha} \mathrm{m} \mathrm{h}^{-1} \mathrm{a}^{-1}\right), \mathrm{K}$ is the soil erodibility factor $\left(\mathrm{t} \mathrm{h} \mathrm{MJ} \mathrm{m}^{-1} \mathrm{~mm}^{-1}\right.$ ), $\mathrm{L}$ is the slope length factor without dimension, $\mathrm{S}$ is the slope steepness factor without dimension, $\mathrm{B}$ is the dimensionless factor of biomass-control in water and soil conservation, $\mathrm{E}$ is the dimensionless factor of engineering-control in water and soil conservation, and $\mathrm{T}$ is the dimensionless factor of tillage practices in water and soil conservation. The parameterization of the CSLE model is shown in Table 3, and the detailed method can be found in reports of related research [30-34]. 
Table 3. The parameterization of the CSLE model.

\begin{tabular}{|c|c|c|c|}
\hline Factor & Formula & Formula Description & Data Source \\
\hline Rainfall erosivity factor (R) [30] & $R=0.179 \sum_{i=1}^{12} P_{i}^{1.5527}$ & $P_{i}$ is the precipitation per month $(\mathrm{mm})$. & $\begin{array}{l}\text { National Meteorological Information } \\
\text { Center (http://data.cma.cn). }\end{array}$ \\
\hline Soil erodibility factor (K) [31] & $\begin{aligned} K=0.1317\{0.2+ & \left.0.3_{\operatorname{exo}}\left[-0.0256 S_{A N}\left(1-\frac{S_{I L}}{100}\right)\right]\right\} \\
& \times\left(\frac{S_{I I}}{C_{L A}-S_{I L}}\right)^{0.3} \\
& \left.\times 1-\frac{0.25 C_{t}}{C_{t}+\exp \left(3.72-0.95 C_{t}\right)}\right] \\
& \times\left(1-\frac{0.7 S_{N I}}{S_{N I}+\exp \left(-5.51+22.9 S_{N I}\right)}\right) \\
L S=(\lambda / 22.1)^{m} \times( & 65.41 \sin \theta+4.56 \sin \theta+0.065)\end{aligned}$ & $\begin{array}{c}S_{A N}, S_{I L}, C_{L A} \text {, and } C_{t} \text { represent the mass fraction of sand grains } \\
(0.05-0.25 \mathrm{~mm}) \text {, silt grains }(0.002-0.05 \mathrm{~mm}) \text {, clay grains }(<0.002 \mathrm{~mm}), \\
\text { and organic matter, respectively. } S_{N 1}=1-S_{A N} / 100 .\end{array}$ & $\begin{array}{l}\text { Soil Science Database of China } \\
\text { (http://vdb3.soil.csdb.cn/). }\end{array}$ \\
\hline Topographical factor (LS) [30] & $m=\left\{\begin{array}{c}0.2, \theta<0.57^{\circ} \\
0.3,0.57^{\circ} \leq \theta<1.72^{\circ} \\
0.4,1.72^{\circ} \leq \theta<2.86^{\circ} \\
0.5,2.86^{\circ} \leq \theta\end{array}\right.$ & $\theta$ is the slope value $\left({ }^{\circ}\right), \lambda$ is the slope length (m). & $\begin{array}{l}\text { Geospatial Data Cloud } \\
\text { (http://www.gscloud.cn/). }\end{array}$ \\
\hline Soil and water conservation factor (BET) & $\begin{array}{l}\text { The soil and water conservation factors were qualitatively estimated } \\
\text { depending on the different land-use types based on the reference } \\
\text { value proposed by previous research and the first-ever nationwide } \\
\text { water resources survey; it was modified according to vegetation } \\
\text { coverage and the data of field investigation units. }\end{array}$ & $\begin{array}{l}\text { The result of biomass-control in water and soil conservation factor is } \\
\text { taken from Huang [32]. } \\
\text { The result of engineering-control in water and soil conservation } \\
\text { factor is taken from Wang et al. [33]. } \\
\text { The result of tillage practices in water and soil conservation factor is } \\
\text { taken from Guo et al. [34]. }\end{array}$ & $\begin{array}{l}\text { MODIS (http://modis.gsfc.nasa.gov/), } \\
\text { Remote Sensing Cloud Mart } \\
\text { (http://www.rscloudmart.com/). }\end{array}$ \\
\hline
\end{tabular}




\subsubsection{Response Dimension}

The response seeks to determine the ability of an ecosystem to repair itself and introduces the concept of ecosystem services. As an indicator of the quantification of ecosystem services, the value of ecosystem services effectively integrates the different ecosystem services provided by the same ecosystem, and this value is then compared with those of other ecosystems [35]. To conduct a thorough review of ecosystem services, we divided them into nine class functions: food production, raw material production, gas regulation, climate regulation, waste treatment, biodiversity maintenance, providing aesthetic value, soil formation and conservation, and hydrological regulation [36]. A method of evaluating an ecosystem service value based on the per unit area that has few data requirements and can be easily operated [37] was selected, and this was suitable for rapidly calculating the ecosystem service value of a small watershed. By using the table showing the Chinese ecosystem service equivalent value per unit area, and collecting the agricultural production statistics of Jiangxi Province, the economic value of the standard ecosystem service equivalent value factor of Jiangxi Province in 2015 was calculated to be $2544 \mathrm{CNY} \mathrm{ha}{ }^{-1}$. After calculating the weight of each ecosystem service function using the entropy weight method, the value of the ecosystem services was evaluated for the small watershed in Xiaoyang.

\subsection{Self-Organizing Map Methodology}

The self-organizing map (SOM) was developed by Kohonen [23] and is an unsupervised artificial system that can emulate certain mappings that occur in the human brain via competitive learning. The method employed can be divided into the following steps:

Step 1: Initialize the network. A basic SOM network consists of an input layer and a Kohonen layer. The input layer is composed of high-dimensional data that need to be clustered. The Kohonen layer is usually arranged on a one- or two-dimensional grid. Each input unit is connected to each output unit via a random initial value weight vector.

Step 2: Select the feature parameter matrix of samples as the input layer for the SOM.

Step 3: Calculate the Euclidean distance between each input vector and the weight vector of each output unit in the Kohonen layer using:

$$
d_{j}=\left\|X-W_{j}\right\|=\sqrt{\sum_{i=1}^{m}\left(x_{i}(t)-w_{i j}(t)\right)^{2}},
$$

where $x_{i}(t)$ is the input of a node, $w_{i j}(t)$ is the link weight of the input nodes $i$ and $j$ at time $t$, and $m$ is the number of input neurons. The neuron with the minimum Euclidean distance is calculated and denoted as the winning neuron $\left(j^{*}\right)$.

Step 4: Define the winning neighborhood. The weight adjustment domain $\left(S_{j}(t)\right)$ at time $t$ is determined with the winning neuron $j^{*}$ as the center. During the training process, $S_{j}(t)$ shrinks with the training time $t$.

Step 5: Undertake weight learning. Adjust the weight of neurons in the winning neighborhood using:

$$
\Delta w_{i j}=\eta h\left(j, j^{*}\right)\left(x_{i}-w_{i j}\right)
$$

where $\eta$ is the learning rate parameter with $0<\eta<1$ and $h\left(j, j^{*}\right)$ is the neighborhood kernel around the winning neuron $j^{*}$, which is defined as:

$$
h\left(j, j^{*}\right)=\exp \left(-\frac{\left|j-j^{*}\right|^{2}}{\sigma^{2}}\right),
$$

where $\sigma$ is the neighborhood radius, which typically decreases with time $t$. 
Step 6: Calculate the output $O_{k}$ using:

$$
O_{k}=f\left(\min \left\|X-W_{j}\right\|\right)
$$

where $f(x)$ is a $0-1$ function or another nonlinear function.

Step 7: Return to Step 2 until a pre-defined maximum number of iteration steps is reached.

To select an "appropriate" number of partitions, the average silhouette width is used to measure cluster validity achieved by the SOM network [38]. The silhouette width combines the cohesion (a) and separation $(b)$ of the cluster, which are defined as:

$$
s(i)=\frac{b(i)-a(i)}{\max \{a(i), b(i)\}},
$$

where $a(i)$ is the average dissimilarity between $i$ and all other objects of its cluster, and $b(i)$ is the minimum average dissimilarity between $i$ and all objects of a cluster that is different from its cluster. When one cluster contains only a single object, $s(i)$ is defined as zero. To evaluate the result of all feature vectors in the entire data set, the average silhouette width is defined as:

$$
S C=\frac{1}{n} \sum_{i=1}^{n} s(i)
$$

where $n$ is the total number of objects in the data set. From the above definition, it is evident that $-1 \leq$ $S C \leq 1$, and the clustering effect is superior when the value of $S C$ is higher.

\section{Results}

\subsection{Soil Erosion Sensitivity}

The spatial pattern of soil erosion sensitivity within the Xiaoyang watershed is shown in Figure 2. Six classes of soil erosion sensitivity were determined to be in the watershed: insensitive, slightly sensitive, moderately sensitive, sensitive, highly sensitive, and extremely sensitive. Areas that were insensitive and slightly sensitive accounted for approximately $79 \%$ and $13 \%$ of the total area, respectively, which shows that soil erosion sensitivity in this watershed was generally low. Approximately $5 \%$ of areas were determined to be moderately sensitive; their distribution was relatively scattered and mainly in areas with a high relief. Areas found to be sensitive and extremely sensitive were mainly distributed in the northeastern and central construction land of the watershed, as well as in farmland areas in the western watershed, but they collectively accounted for approximately $3 \%$ of the total area.

\subsection{Soil Erosion Condition}

The area suffering from soil erosion in the Xiaoyang watershed measured $9.8 \mathrm{~km}^{2}$ and accounted for $26.05 \%$ of the total area. Figure 3 shows the distribution of the soil erosion condition within the Xiaoyang watershed. The watershed was generally dominated by slight erosion in the northwestern and eastern areas of the watershed. Slight erosion mostly occurred in areas with a slope of $6^{\circ}-15^{\circ}$, and moderately eroded areas were scattered around areas that were slightly eroded and had slopes of $8^{\circ}-20^{\circ}$ and vegetation coverage of $50-60 \%$. A few severely and highly eroded areas were found in the northwestern, southwestern, and northeastern areas of the watershed where the slope was mainly $>15^{\circ}$ and the vegetation coverage was $<45 \%$. 


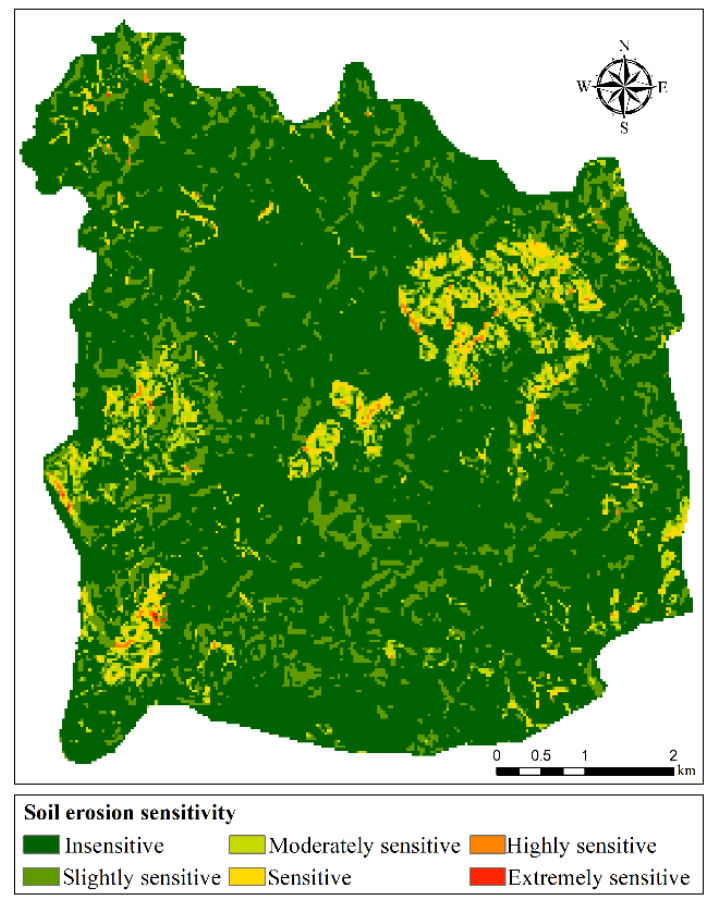

Figure 2. The spatial pattern of soil erosion sensitivity in the Xiaoyang watershed.

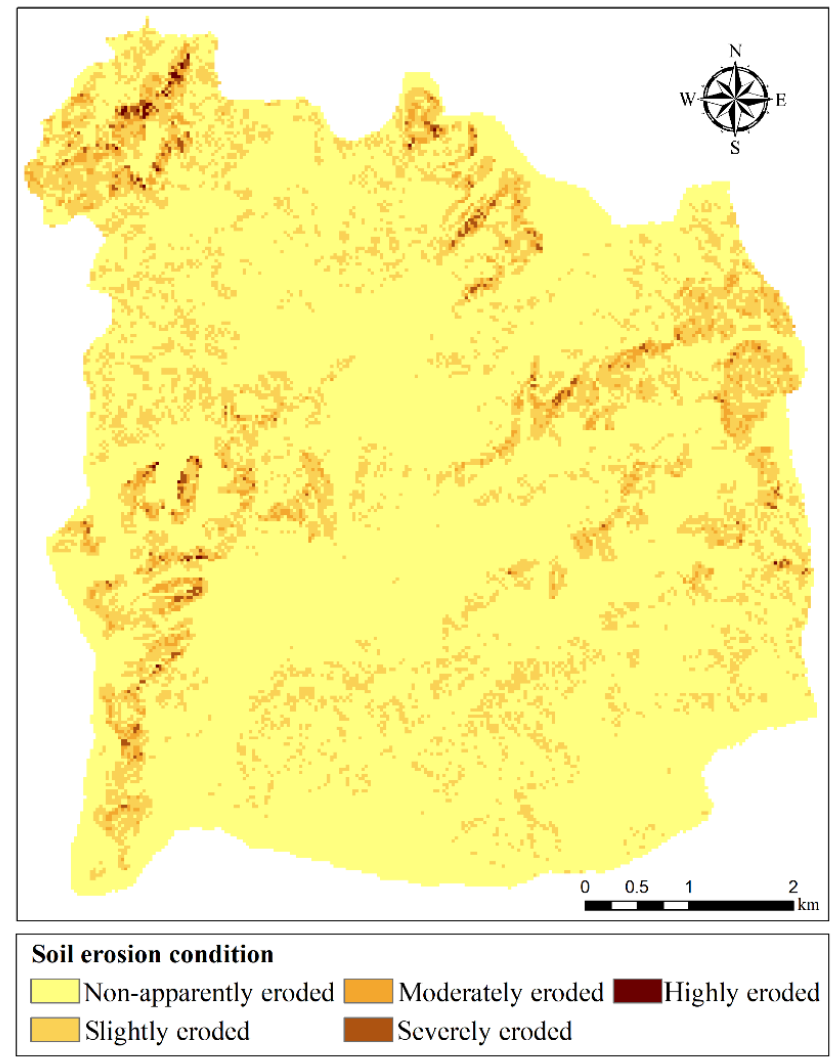

Figure 3. The spatial pattern of soil erosion conditions in Xiaoyang watershed.

\subsection{Value of Ecosystem Services}

As shown in Figure 4, the total value of the ecosystem services within the Xiaoyang watershed in 2015 was 187.84 million CNY. With respect to the land use type, forestry provided the highest total service value of 156.37 million CNY at $83.25 \%$ of the total value, while other types of land use accounted for less than $20 \%$. Bare land provided the lowest ecosystem service value and accounted for 
only $0.01 \%$ of the total value. Costanza et al. [39] found the value of construction land to be negligible; therefore, it was not considered in this study. In terms of the economic value derived from different types of ecosystem services, the values of each ecosystem service were considered to be equivalent. The value of soil formation and conservation was the highest at more than 3.30 million CNY, followed by hydrological regulation ( 2.91 million CNY), where they account for $18 \%$ and $15 \%$ of the total value, respectively. Gas regulation, biodiversity maintenance, climate regulation, and raw material production follow closely and collectively account for approximately $50.41 \%$ of the total service value. Other ecological services had a low value and together accounted for $16.54 \%$ of the total service value.

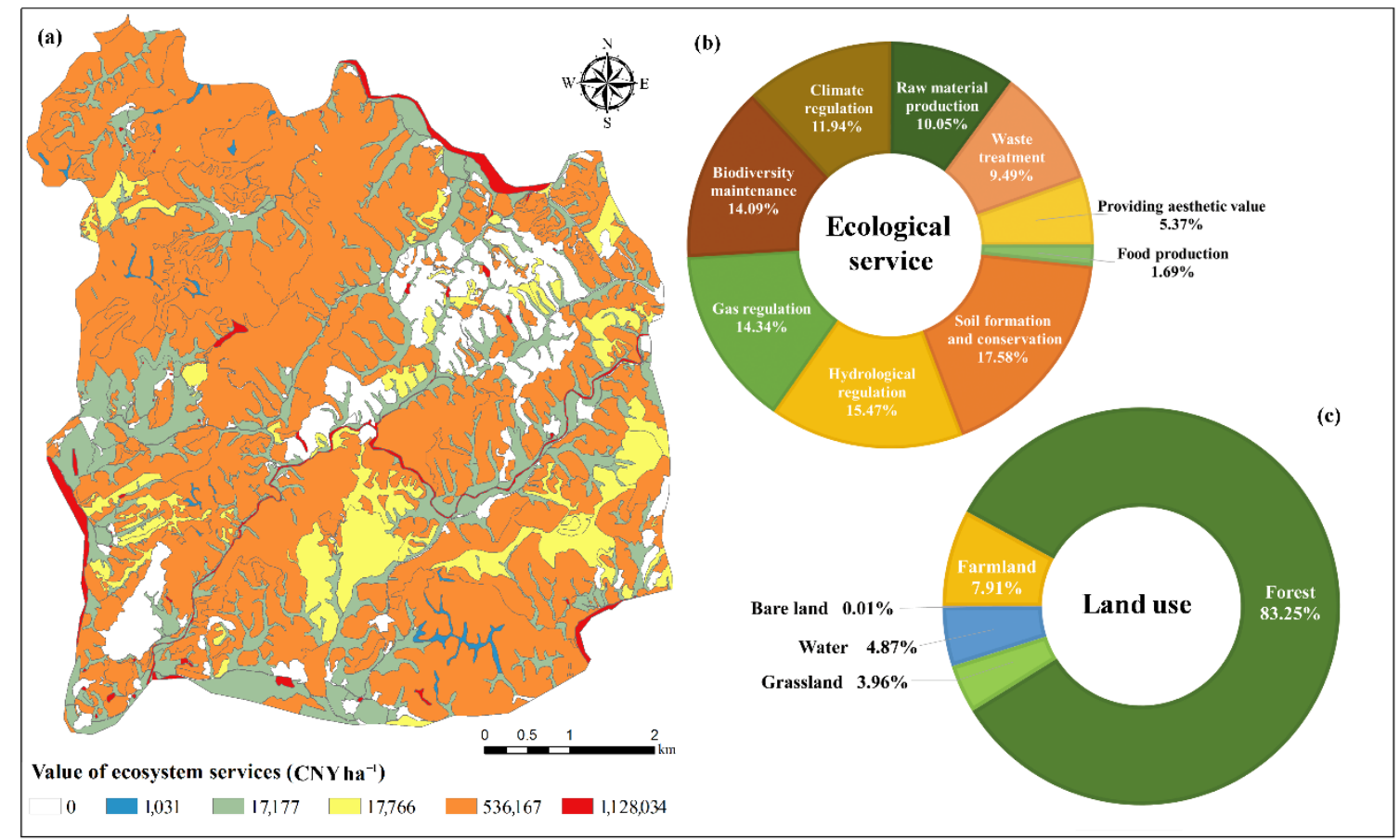

Figure 4. Ecosystem service values within the Xiaoyang watershed: (a) spatial distribution of total value, (b) proportion of values for different land-use types, and (c) proportion of values for different ecological service types.

\subsection{Soil and Water Conservation Partitioning}

To provide replicate measurements of raster data within each cell, the soil and water conservation regions for the Xiaoyang small watershed were defined based on a spatial framework provided by a 30-m grid comprising 52,094 cells.

When creating the SWCP in the past, it was challenging to objectively determine the number of partitions within a study area, and it was easier to make a subjective decision. In the present study, the exact number of clusters was not initially known; therefore, the topology of the Kohonen layer was designed as a one-dimensional $\left(1^{*} \mathrm{C}\right)$ grid with numbers varying from 2 to $8(2 \leq C \leq 8)$ under investigation. We selected the Xiaoyang small watershed feature parameter matrix as an input layer for the SOM, which contained three soil and water conservation variables. To determine the optimum number of clusters, the average silhouette width was calculated (described in Equation (8)), as shown in Figure 5. The average silhouette width criterion determined six to be the optimal number of clusters, and the small watershed was finally divided into five regions (one cluster was null).

Certain non-zonal factors existed in the indicator system, such as slope and land use, which could affect the zonal distribution of the SWCP results. In addition, due to the small spatial unit used in the SWCP, there was a tendency for a large number of isolated samples with small areas (but unique properties) to appear in the clustering result. These fragmented areas made it difficult to carry out soil and water conservation measures. In order to ensure the continuity and integrity of the partitioning 
results, filter and trend-surface analyses were used to make choices regarding the spatial extent of the partitioning results, removing the debris maps and smoothing the boundary of partition, and finally obtained the SWCP map of the Xiaoyang watershed (Figure 6).

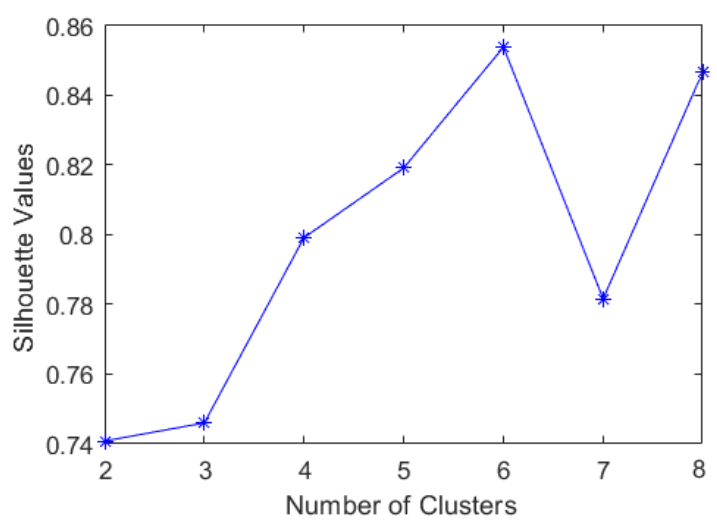

Figure 5. Silhouette values for different cluster numbers from the self-organizing map (SOM) results.

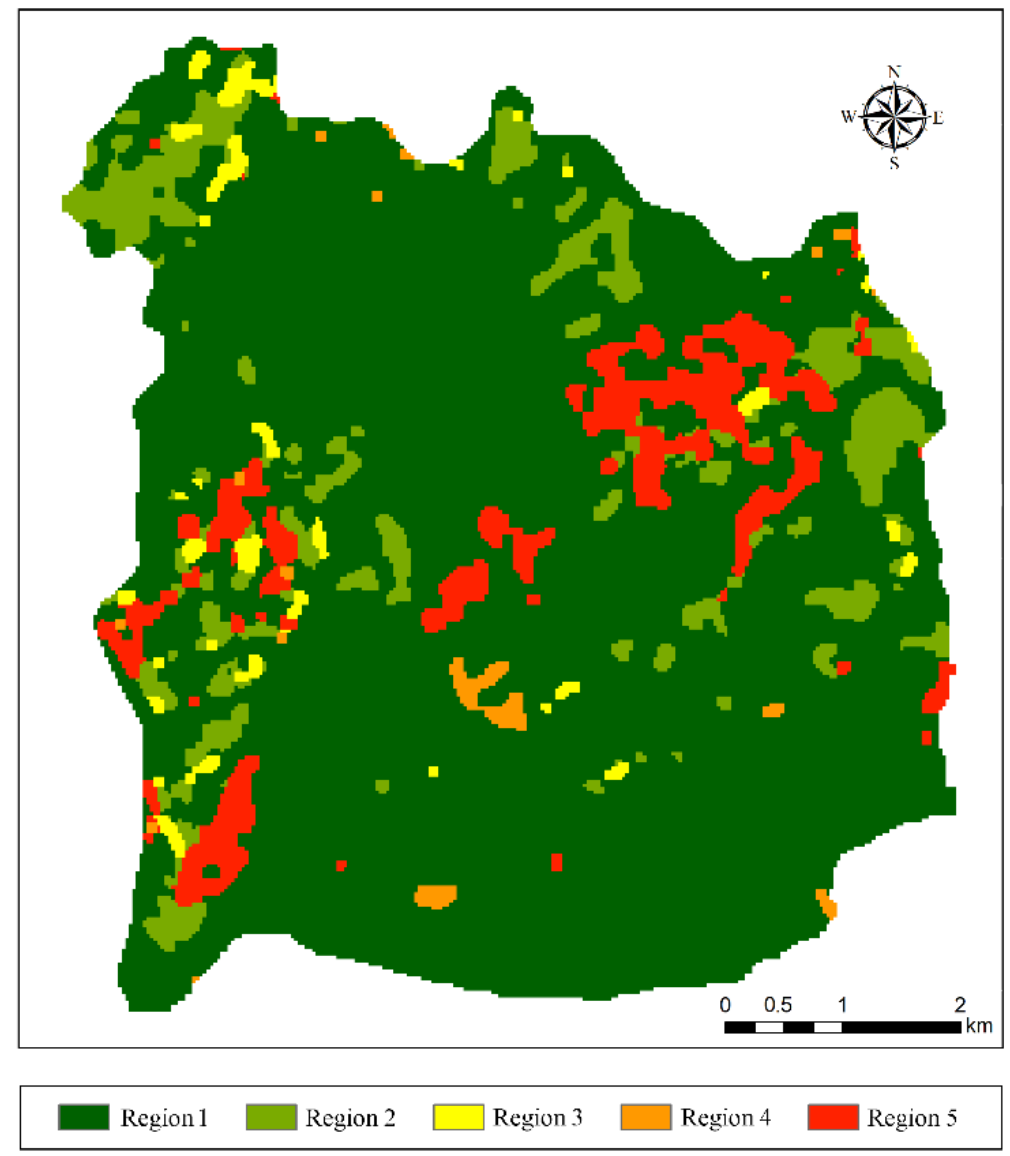

Figure 6. Soil and water conservation partitioning of the Xiaoyang watershed.

The largest part of the Xiaoyang watershed was region 1, which accounted for approximately $82 \%$ of the total area. No obvious soil erosion occurred in this region, and the soil erosion sensitivity could be ignored. Region 2 accounted for $9 \%$ of the watershed; slight erosion mainly occurred in this region, but the possibility of soil erosion was extremely low. Forest land was the main land-use type in region 2 , which gave it the highest ecosystem service value of the five regions. Region 3 accounted for $1.74 \%$ of the watershed; it suffered the most serious soil erosion, and the soil erosion sensitivity of this region ranged from slight to severe. Region 4 accounted for less than $1 \%$ of the total area and was sporadically 
distributed in the central part of the watershed, as well as the northern, northeastern, and southeastern areas of the watershed edges. Region 4 experienced almost no soil erosion, but it had a high soil erosion sensitivity because of its large slopes and low vegetation coverage. The remaining areas were classified as Region 5, which mainly occurred on a diagonal from the northeast to the southwest of the small watershed and accounted for $7 \%$ of the total area. Construction land and farmland with low vegetation coverage were the main land-use types in this region. Region 5 had a relatively dense population, which suggests that it experienced the strongest environmental influence from human activities, which resulted in its sensitivity to soil erosion.

\section{Discussion}

\subsection{Selection of the Partitioning Method}

A wide range of partitioning methods are available, and each has strengths and weaknesses: no single partitioning method can be used for all purposes and none performs well in all places $[8,40,41]$. This section discusses the rationality for selecting the SWCP method in different scenarios.

The partitioning unit differs depending on whether it is applied to a normative or functional region, according to the statistical office of the European Communities [42]. The spatial unit of a normative region is defined by official or normative aggregations and expresses political objectives. The SWCP in China is based on a normative region developed by the Ministry of Water Resources of the People's Republic of China in 2011: it is recommended that county-level administrative units are the spatial unit employed and these relate to natural and social conditions, the type and intensity of soil erosion, and the amount of damage incurred [11]. Based on this unit, the characteristics and distribution of regional soil erosion can be determined, and the results can be used to make regional and ultimately national soil and water conservation strategies and plans. However, as study areas are nonhomogeneous, many factors of the SWCP need to be considered on a country scale. The SWCP was developed to guide the region-specific management of soil erosion, which is mainly achieved by local governments. As statistics relating to natural resources and socio-economic data that are used in partitioning and the design and implementation of soil and water conservation projects are obtained by the government, normative regions that maintain the integrity of administrative boundaries are appropriate for use with SWCP on country and province scales.

However, as the spatial distribution of soil erosion is not directly controlled by administrative boundaries, the soil erosion situation and future development directions of one normative region cannot be highlighted similarities inside. It might cause an ecological fallacy in subsequent analysis based on this kind of partition [43]. Additionally, the SWCP in small watersheds requires high-precision data to determine specific soil and water conservation measures; therefore, it is not necessary to base the formulation and application of partitioning on administrative units. The SWCP in this paper, therefore, adopts functional regions. The spatial units of functional regions are defined by geographical and socio-economic criteria and are thus directly related to phenomena. Compared with normative regions, functional regions are applicable for use on a global scale, as they can be used to reflect the cause and status of soil erosion without proposing soil and water conservation management objectives, or for use in a small watershed to propose specific soil erosion control schemes that can be implemented by one local government or competent agency.

From a technical perspective, methods used to conduct partitioning can be divided into manual methodologies and automated methodologies. Previous SWCP schemes, such as "the map of soil erosion in the Middle Yellow River" and "the map of soil erosion types in China" [9,10] were based on manual methodologies. Such methods are subjective and easily influenced by the analyst's opinion. Furthermore, as data are now more accurate, the volume of spatial data increases, making it more difficult to adopt a manual methodology to conduct partitioning, and automated methodologies are thus being increasingly used in SWCP. 
Mainstream automated methodologies can be divided into supervised learning and unsupervised learning, which are based on learning methods. Supervised learning is a top-down classification method based on prior knowledge, such as the number and type of regions to be designed [44]. For example, China's key prevention and control regions for soil and water loss were developed using a supervised learning method in accordance with the National Plan for Soil and Water Conservation [45]. Supervised learning is useful for enabling the partitioning of soil erosion types, but it is not so applicable for SWCP in a small watershed because the type of region is determined by mature soil and water conservation schemes instead of analyzing the current regional situation and development.

Unsupervised learning is a bottom-up clustering method that does not use prior knowledge [46]. Distinct soil erosion regimes are first identified based on evolutionary rules and the driving mechanisms behind soil erosion, and the specific control schemes of soil erosion are then identified and the requirements for socio-economic development are added. The SOM model is a relatively mature unsupervised learning method that is appropriated for partitioning. The operational process of SOM is to cluster the spatial units in the research area according to characteristic parameters and to then connect the spatial units with the spatial position to form areas with different typologies. Many researchers believe that partitioning using automated methodologies is based on the values of the characteristic parameters themselves, which neither considers the hierarchical relationship between indexes nor recognizes the differences between dominant factors in each partition. However, this limitation should not restrict us from using fast, quantitative, automated methodologies. Therefore, to partition the interaction between human activities, the ecological environment, and soil erosion rather than the variable itself, this study used the PSR framework to qualitatively classify the SWCP indicators prior to conducting clustering based on SOM.

It is of note that we cannot quantitatively assess which automated methodology is superior. When considering different characteristics, one methodology may be superior in one place and not so applicable in another. Therefore, we can only conduct a matching analysis based on classification methods and regional targets to guide the selection of a suitable partitioning method.

\subsection{Suggested Mitigation Measures Based on SWCP}

A small watershed is not only a geographical structure unit but also a spatial unit in which soil erosion is comprehensively managed by the Chinese government. The main objective of comprehensively managing a small watershed is to conserve soil and water, enhance the environment, and improve economic returns [47]. Therefore, based on the spatial differentiation of soil and water conservation characteristics in SWCP, and depending on the partitioning results, specific suggestions for conserving soil and water and mitigating the scarcity of ecosystem services can enhance social benefits.

When discussing the configuration of soil and water conservation measures, we mainly analyzed the characteristics of different regions to conduct a suitable arrangement of vegetation measures in terms of the surface shape. There was minimal soil erosion in region 1; therefore, it is not necessary to arrange soil and water conservation measures. Soil erosion occurred at a low intensity in region 2; therefore, it can recover naturally. The closing hillside for erosion control is a method that uses an area's natural remediation ability supplemented by artificial replanting and tending, which promotes vegetation restoration, controls soil erosion, and improves the ecological environment [48]. The process of ecological restoration can be accelerated by implementing the closing hillside in region 2 .

Soil erosion was slightly higher in region 3 than in region 2 within the small Xiaoyang watershed. A scheme could be designed that increases vegetation coverage and provides economic benefits to farmers. One of the important measures used to develop soil and water resources is to plant fruit forests since this enables a reduction in the use of water and fertilizer and provides obvious ecological benefits. Fruit forests also provide a short operating cycle and high economic benefits, which effectively increase the income of residents in soil erosion areas. The Xiaoyang small watershed is the main production area for Gannan navel oranges, which are a national product of geographical indication in China and can be grown on bench terraces or horizontally, in level ditches, or with other land preparation 
methods; these could be planted in region 3. However, a monotonous chamaephyte structure can cause increased ecological and economic risks; therefore, measures supporting the planting of economic fruit forests require further study.

Region 4 suffers from severe soil erosion, and the key objective in this region is to prevent its further occurrence. Therefore, trees and forests with a low canopy density should be planted on bare land following the selection of appropriate tree species and the intercropping mode with respect to existing vegetation. During the construction of soil and water conservation forests, it is also necessary to consider soil erosion in Pinus massoniana woodlands. Pinus massoniana is a representative tree species in the Xiaoyang small watershed. Due to human disturbances and the lack of understory vegetation, soil erosion is serious within Pinus massoniana woodlands [49]. It is thus necessary to conduct microslope reconstruction, replant the understory, and to make enclosures to ensure conservation.

Most of region 5 has a slope $<25^{\circ}$; therefore, agriculture measures can be employed in soil and water conservation, particularly on terraces, supplemented by slope treatment for erosion control and hardened field roads. For areas in which laying terraces is difficult, the land utilization rate can be improved using rational close planting and intercropping, if the soil fertility is good; otherwise, no or less tillage should be implemented to protect the soil.

\section{Conclusions}

Partitioning for soil and water conservation within small watersheds plays a significant role in selecting the optimum soil and water conservation measures that can be planned and implemented. This study presents a method using the SOM with SWCP within a small watershed. The PSR framework was used to construct an indicator system consisting of three factors: soil erosion sensitivity, the soil erosion condition, and ecosystem services. Ecosystem services were introduced into the soil and water conservation evaluation indicator system to reflect the contribution that the small watershed ecosystem provides to humans and nature. Using these three indicators as sample data, the SOM method was then employed to conduct partitioning. By evaluating the silhouette width of the clustering results, the optimal scheme was selected, where the small watershed was divided into five regions that covered $81.46 \%, 8.86 \%, 1.74 \%, 0.85 \%$, and $7.09 \%$ of the Xiaoyang watershed respectively. Region-specific measures can now be arranged according to the partitioning results.

In this study, the indicator system based on the PSR model provides a better understanding of the interactions between soil erosion and the ecosystem, and a higher comprehensibility of a selection of mitigation measures for the comprehensive control of soil erosion. From a technical perspective, the SOM method is more automatic and efficient, and can provide a more detailed identification of different regions. This scheme lays the scientific basis for local management agencies to implement region-specific mitigation measures and improves the integrative benefit. However, we acknowledge that subjective decisions remain for partitioning methods, such as the size of spatial units and iterations for clustering.

Author Contributions: Conceptualization, Z.L.; data curation, X.H. and K.N.; formal analysis, L.W.; investigation, D.W.; methodology, L.W. and D.W.; supervision, Z.L.; visualization, L.W.; writing—original draft, L.W.; writing-review and editing, Z.L. and D.W. All authors have read and agree to the published version of the manuscript.

Funding: This research was funded by the National Key Research and Development Program of China, grant number 2017YFC0505401.

Acknowledgments: We thank Tianwei Wang and Cheng Liu for the data acquisition.

Conflicts of Interest: The authors declare no conflict of interest.

\section{References}

1. Prosdocimi, M.; Tarolli, P.; Cerdà, A. Mulching practices for reducing soil water erosion: A review. Earth Sci. Rev. 2016, 161, 191-203. [CrossRef] 
2. Amundson, R.; Berhe, A.A.; Hopmans, J.W.; Olson, C.; Sztein, A.E.; Sparks, D.L. Soil science. Soil and human security in the 21st century. Science 2015, 348, 1261071. [CrossRef]

3. Colman, C.B.; Oliveira, P.T.S.; Almagro, A.; Soares-Filho, B.S.; Rodrigues, D.B.B. Effects of Climate and Land-Cover Changes on Soil Erosion in Brazilian Pantanal. Sustainability 2019, 11, 7053. [CrossRef]

4. Jia, L.; Zhao, W.; Zhai, R.; Liu, Y.; Kang, M.; Zhang, X. Regional differences in the soil and water conservation efficiency of conservation tillage in China. Catena 2019, 175, 18-26. [CrossRef]

5. Chen, J.; Xiao, H.; Li, Z.; Liu, C.; Wang, D.; Wang, L.; Tang, C. Threshold effects of vegetation coverage on soil erosion control in small watersheds of the red soil hilly region in China. Ecol. Eng. 2019, 132, 109-114. [CrossRef]

6. Kessler, C.A. Decisive key-factors influencing farm households' soil and water conservation investments. Appl. Geogr. 2006, 26, 40-60. [CrossRef]

7. Zhao, G.; Mu, X.; Wen, Z.; Wang, F.; Gao, P. Soil Erosion, Conservation, and Eco-Environment Changes in the Loess Plateau of China. Land Degrad. Dev. 2013, 499-510. [CrossRef]

8. Liu, Y.; Li, T.; Zhao, W.; Wang, S.; Fu, B. Landscape functional zoning at a county level based on ecosystem services bundle: Methods comparison and management indication. J. Environ. Manag. 2019, 249, 109315. [CrossRef]

9. Huang, B. A preliminary draft of comprehensive physical regionalization in China. Acta Geogr. Sin. 1958, 24, 348-364. (In Chinese)

10. Wang, D.; Li, Z.; Zeng, G.; Nie, X.; Liu, C. Evaluation of Regionalization of Soil and Water Conservation in China. Sustainability 2018, 10, 3320. [CrossRef]

11. Zhao, Y.; Wang, Z.; Sun, B.; Zhang, C.; Ji, Q.; Feng, L.; Shi, M. A study on scheme of soil and water conservation regionalization in China. J. Geogr. Sci. 2013, 23, 721-734. [CrossRef]

12. Peng, J.; Ma, J.; Yuan, Y.; Wei, H.; Pang, W. Integrated Urban Land-Use Zoning and Associated Spatial Development: Case Study in Shenzhen, China. J. Urban Plan. Dev. 2015, 141. [CrossRef]

13. Liu, Y.; Guo, S. Present status and characteristics of soil and water conservation of the small watershed management in China. Soil Water Conserv. China 1988, 11, 22-25. (In Chinese) [CrossRef]

14. Zhang, H.; Zhang, C.; Zhao, Y.; Chang, D.; Cheng, J. Issues and countermeasures in the comprehensive management of small watershed in China. Sci. Soil Water Conserv. 2016, 14, 131-137. (In Chinese) [CrossRef]

15. Yan, Z. Study on Soil and Water Consrvation Regionalization and Function Orientation. Ph.D. Thesis, Beijing Forestry University, Beijing, China, 2013. (In Chinese).

16. Lan, W. Function and Value of Soil and Water Conservation Ecololgical Services. Ph.D. Thesis, Beijing Forestry university, Beijing, China, 2007. (In Chinese).

17. Zheng, H.; Li, Y.; Robinson, B.E.; Liu, G.; Ma, D.; Wang, F.; Lu, F.; Ouyang, Z.; Daily, G.C. Using ecosystem service trade-offs to inform water conservation policies and management practices. Front. Ecol. Environ. 2016, 14, 527-532. [CrossRef]

18. Zhang, J.; Li, X.; Buyantuev, A.; Bao, T.; Zhang, X. How Do Trade-Offs and Synergies between Ecosystem Services Change in the Long Period? The Case Study of Uxin, Inner Mongolia, China. Sustainability 2019, 11, 6041. [CrossRef]

19. Carpenter, S.R.; Mooney, H.A.; Agard, J.; Capistrano, D.; DeFries, R.S.; Díaz, S.; Dietz, T.; Duraiappah, A.K.; Oteng-Yeboah, A.; Pereira, H.M. Science for managing ecosystem services: Beyond the Millennium Ecosystem Assessment. Proc. Natl. Acad. Sci. USA 2009, 106, 1305-1312. [CrossRef]

20. Feng, X.; Fu, B.; Piao, S.; Wang, S.; Ciais, P.; Zeng, Z.; Lü, Y.; Zeng, Y.; Li, Y.; Jiang, X.; et al. Revegetation in China's Loess Plateau is approaching sustainable water resource limits. Nat. Clim. Chang. 2016, 6, 1019-1022. [CrossRef]

21. Chen, L.; Wei, W.; Fu, B.; Lü, Y. Soil and water conservation on the Loess Plateau in China: Review and perspective. Prog. Phys. Geogr. Earth Environ. 2016, 31, 389-403. [CrossRef]

22. Rawat, W.; Wang, Z. Deep Convolutional Neural Networks for Image Classification: A Comprehensive Review. Neural Comput. 2017, 29, 2352-2449. [CrossRef]

23. Mannan, A.; Chaudhary, S.; Dhanya, C.T.; Swamy, A.K. Regionalization of rainfall characteristics in India incorporating climatic variables and using self-organizing maps. ISH J. Hydraul. Eng. 2017, 24, 147-156. [CrossRef] 
24. Wang, S.; Xu, X.; Tang, Q.; Liu, M.; Yu, J. A Study on Eco-Hydrology Regionalization and Its Application. In Proceedings of the 2010 4th International Conference on Bioinformatics and Biomedical Engineering, Chengdu, China, 18-20 June 2010; pp. 1-6.

25. Hughey, K.F.; Cullen, R.; Kerr, G.N.; Cook, A.J. Application of the pressure-state-response framework to perceptions reporting of the state of the New Zealand environment. J. Environ. Manag. 2004, 70, 85-93. [CrossRef] [PubMed]

26. McGeoch, M.A.; Butchart, S.H.M.; Spear, D.; Marais, E.; Kleynhans, E.J.; Symes, A.; Chanson, J.; Hoffmann, M. Global indicators of biological invasion: Species numbers, biodiversity impact and policy responses. Divers. Distrib. 2010, 16, 95-108. [CrossRef]

27. Li, Y.; Sun, M.; Yuan, G.; Zhou, Q.; Liu, J. Study on Development Sustainability of Atmospheric Environment in Northeast China by Rough Set and Entropy Weight Method. Sustainability 2019, 11, 3793. [CrossRef]

28. Peng, J.; Wu, W.H.; Liu, Y.X.; Hu, Y. Soil conservation service zoning in the Inner Mongolia Autonomous Region based on PSR framework. Acta Ecol. Sin. 2017, 37, 3849-3861. (In Chinese) [CrossRef]

29. Sun, X.; Zhou, Z.; Chen, Q.; Chen, J.; Zhang, S. Sensitivity Evaluation and the Spatial Distribution of Soil Erosion Key Ecological Function Areas: A Case of Leishan City of Guizhou. J. Soil Water Conserv. 2016, 30, 73-78. (In Chinese) [CrossRef]

30. Wischmeier, W.H.; Smith, D.D. Predicting Rainfall Erosion Losses: A Guide to Conservation Planning (No. 537); Department of Agriculture, Science and Education Administration: Beltsville, MD, USA, 1978.

31. Williams, J.R.; Renard, K.G.; Dyke, P.T. EPIC: A new method for assessing erosion's effect on soil productivity. J. Soil Water Conserv. 1983, 38, 381-383.

32. Huang, Y. Study on Soil Erosion and Scenario Analysis of Soil and Water Conservation Based on CSLE Model: A Case Study on the Small Watershed of Xiejia in Ninghua County. Master's Thesis, Fujian Normal University, Fujian, China, 2017. (In Chinese).

33. Wang, K.; Xia, Y.; Ma, J.; Qu, C. Quantitative Assessment of Soil Erosion in Gushanchuan Watershed Based on CSLE and High-Resolution Aerial Images. Res. Soil Water Conserv. 2015, 22, 26-32. (In Chinese)

34. Guo, Q.; Liu, B.; Zhu, S.; Wang, G.; Liu, Y.; Wang, A. Main factors of soil and water conservation tillage measures in China. Soil Water Conserv. China 2013, 22-26. (In Chinese) [CrossRef]

35. Xie, G.D.; Zhang, C.X.; Zhen, L.; Zhang, L.M. Dynamic changes in the value of China's ecosystem services. Ecosyst. Serv. 2017, 26, 146-154. [CrossRef]

36. Xie, G.; Zhen, L.; Lu, C.; Xiao, Y.; Li, W. Applying Value Transfer Medthod for Eco-Service Valuation in China. J. Resour. Ecol. 2010, 1, 51-59. [CrossRef]

37. Xie, G.; Zhang, C.; Zhang, L.; Chen, W.; LI, S. Improvement of the Evaluation Method for Ecosystem Service Value Based on Per Unit Area. J. Nat. Resour. 2015, 30, 1243-1254. (In Chinese) [CrossRef]

38. Rousseeuw, P.J. Sillhouettes a graphical aid to the interpretation and validation of cluster analysis. J. Comput. Appl. Math. 1987, 20, 53-65. [CrossRef]

39. Costanza, R.; d'Arge, R.; de Groot, R.; Farber, S.; Grasso, M.; Hannon, B.; Limburg, K.; Naeem, S.; O'neill, R.V.; Paruelo, J. The value of the world's ecosystem services and natural capital. Nature 1997, 387, 253. [CrossRef]

40. Duque, J.C.; Ramos, R.; Suriñach, J. Supervised Regionalization Methods: A Survey. Int. Reg. Sci. Rev. 2016, 30, 195-220. [CrossRef]

41. Praskievicz, S.; Luo, C. Unsupervised hydrologic classification of rivers: Watershed controls on natural and anthropogenic flow regimes, Alabama, USA. Hydrol. Process. 2019, 33, 1231-1244. [CrossRef]

42. Nomenclature of Territorial Units for Statistics-NUTS: Statistical Regions of Europe. Available online: https://ec.europa.eu/eurostat/documents/3859598/5883677/KS-BD-04-005-1-EN.PDF/58c27a2d-f60c4475-9d31-f4dcbf95d6b6?version=1.0 (accessed on 10 January 2020).

43. Palmer-Jones, R. Agricultural growth, poverty reduction and agro-ecological zones in India: An ecological fallacy? Food Policy 2003, 28, 423-431. [CrossRef]

44. Pagliero, L.; Bouraoui, F.; Diels, J.; Willems, P.; McIntyre, N. Investigating regionalization techniques for large-scale hydrological modelling. J. Hydrol. 2019, 570, 220-235. [CrossRef]

45. Wang, H.; Zhao, Y. Discuss on several problems of the division standard of key prevention and control region for soil and water loss. Soil Water Conserv. China 2015, 61-63. (In Chinese) [CrossRef]

46. Niesterowicz, J.; Stepinski, T.F.; Jasiewicz, J. Unsupervised regionalization of the United States into landscape pattern types. Int. J. Geogr. Inf. Sci. 2016, 30, 1450-1468. [CrossRef] 
47. Liu, Y. Analysis of Comprehensive Management of Small Watershed. Master's Thesis, Xihua University, Chengdu, China, 2014. (In Chinese).

48. Morgan, R.P.C. Soil Erosion and Conservation; Blackwell Publishing Company: Oxford, UK, 2006.

49. Wang, B.; Wang, Y. Relationships between the characteristics of soil and understory in a Pinus massoniana forest in southern China. Catena 2019, 176, 352-361. [CrossRef]

(C) 2020 by the authors. Licensee MDPI, Basel, Switzerland. This article is an open access article distributed under the terms and conditions of the Creative Commons Attribution (CC BY) license (http://creativecommons.org/licenses/by/4.0/). 